\title{
Thoracoabdominal aorta replacement with branched graft for visceral and segmental artery reimplantation-case report
}

\author{
Kay-Hyun Park^, Jae Hang Lee \\ Department of Thoracic and Cardiovascular Surgery, Seoul National University Bundang Hospital, Seongnam, Korea \\ Correspondence to: Kay-Hyun Park. Department of Thoracic and Cardiovascular Surgery, Seoul National University Bundang, 82 Gumi-ro, 173 beon- \\ gil, Seongnam 13620, Korea. Email: drkhpark@gmail.com, 00913@snubh.org.
}

\begin{abstract}
There are various options in the technique of branch vessel reimplantation during thoracabdominal aortic replacement. The choice of technique may affect the conduct of the operation and even the surgical outcome especially in case of low-volume surgeons. This report describes the procedural details of thoracoabdominal aortic replacement performed in a 42-year-old female Marfan patient who had Crawford type II aneurysm caused by chronic type B dissection. It stresses our technical tips and pitfalls of using a 4-branch graft including determination of adequate graft length, sequence of branch reimplantation, anastomotic technique and measures of organ protection. We also describe a novel technique of intercostal artery reimplantation named by ourselves as "frontage graft". In this technique, target intercostal arteries are sequentially anastomosed to an 8- or 10-mm graft which has both ends connected to the main aortic graft and runs parallel. We believe that branch graft technique for visceral branch reimplantation has advantages such as versatility in dealing with calcified or shaggy aorta, earlier reperfusion of individual branches, ease of controlling the anastomotic bleeding, and prevention of late patch aneurysm. In our experience, frontage graft technique used for intercostal artery reimplantation showed better patency rate than end-to-end interposition grafts with very low rate of spinal cord ischemia.
\end{abstract}

Keywords: Case report; aortic aneurysm; thoracoabdominal aorta (TAA); aortic surgery; prosthetic vascular graft

Received: 24 April 2020; Accepted: 20 August 2020; Published: 20 July 2022.

doi: $10.21037 /$ jovs-20-115

View this article at: http://dx.doi.org/10.21037/jovs-20-115

\section{Introduction}

Aortic surgery such as replacement of the root, arch and thoracoabdominal aorta (TAA) requires reimplantation of branch vessels into the main aortic graft. There are various options in the techniques of branch vessel reimplantation and the preference varies among surgeons and according the target segment replaced (Figures 1,2). The choice of technique may affect the conduct of the operation and even the surgical outcome sometimes. The aim of this article is to describe the technical details of TAA replacement focusing on the reimplantation of segmental arteries and visceral branches using a branched prosthetic graft. We present the following case in accordance with the CARE reporting checklist (available at https://jovs.amegroups.com/article/ view/10.21037/jovs-20-115/rc).

\section{Case presentation}

The technique described here is being used recently in almost all cases of TAA replacement in our center. As long as computed tomographic (CT) image of the aorta in good quality is available, only echocardiographic examination is added to the routine laboratory examinations required for general anesthesia. Identification of the origin of Adamkiewicz artery by additional CT or magnetic resonance imaging is not a part of our preoperative examination.

The patient shown in the video is a 42 -year-old female

^ORCID: 0000-0002-1111-9627. 

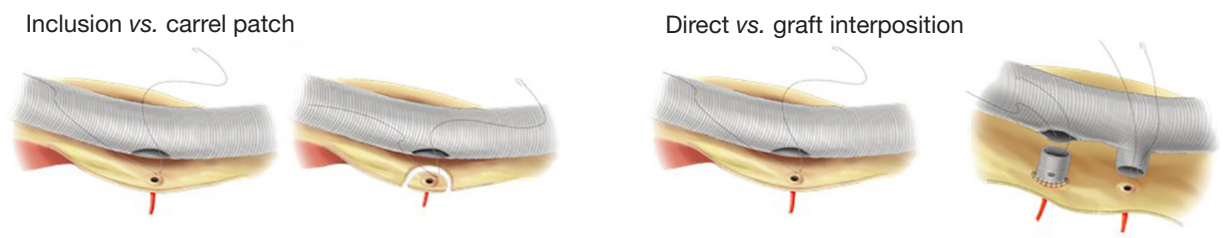

Individual $v s$. en bloc
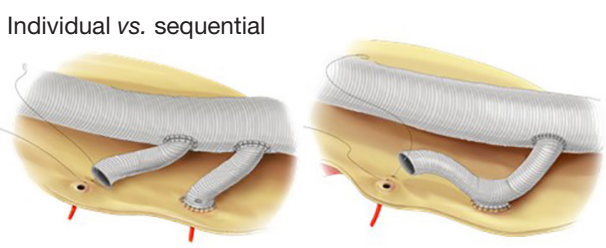

Figure 1 Technical options for branch vessel reimplantation in aortic surgery.
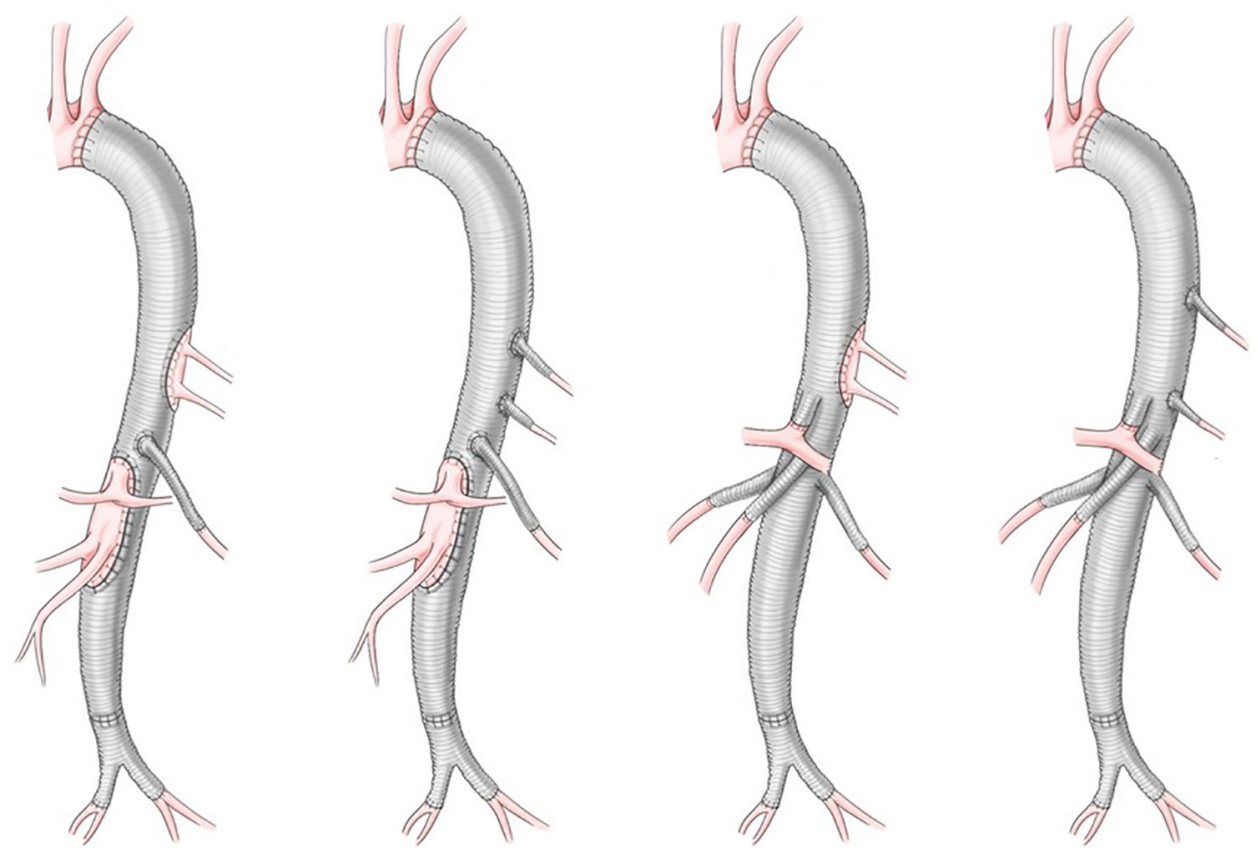

Figure 2 Various combinations of branch vessel reimplantation technique in thoracoabdominal aortic replacement.

who had presented with chronic type B dissection, the aortic root aneurysm, and Marfan syndrome 7 years ago. She underwent valve-sparing root replacement (reimplantation procedure) at that time, during which total arch replacement with classic elephant trunk technique was performed concomitantly. During the follow-up period, the TAA aneurysm of Crawford type II progressively enlarged to reach the maximal diameter of $5.5 \mathrm{~cm}$. All procedures performed in this study were in accordance with the ethical standards of the institutional and/or national research committee(s) and with the Helsinki Declaration (as revised in 2013). Written informed consent was obtained from the patient for publication of this case report and accompanying images. A copy of the written consent is available for review by the editorial office of this journal.

For anesthesia, double-lumen tube was inserted into the trachea. Arterial pressure monitoring catheters were inserted into the right radial and femoral arteries. A largebore triple-lumen catheter was inserted into the right internal jugular vein. Additional monitoring equipment were 


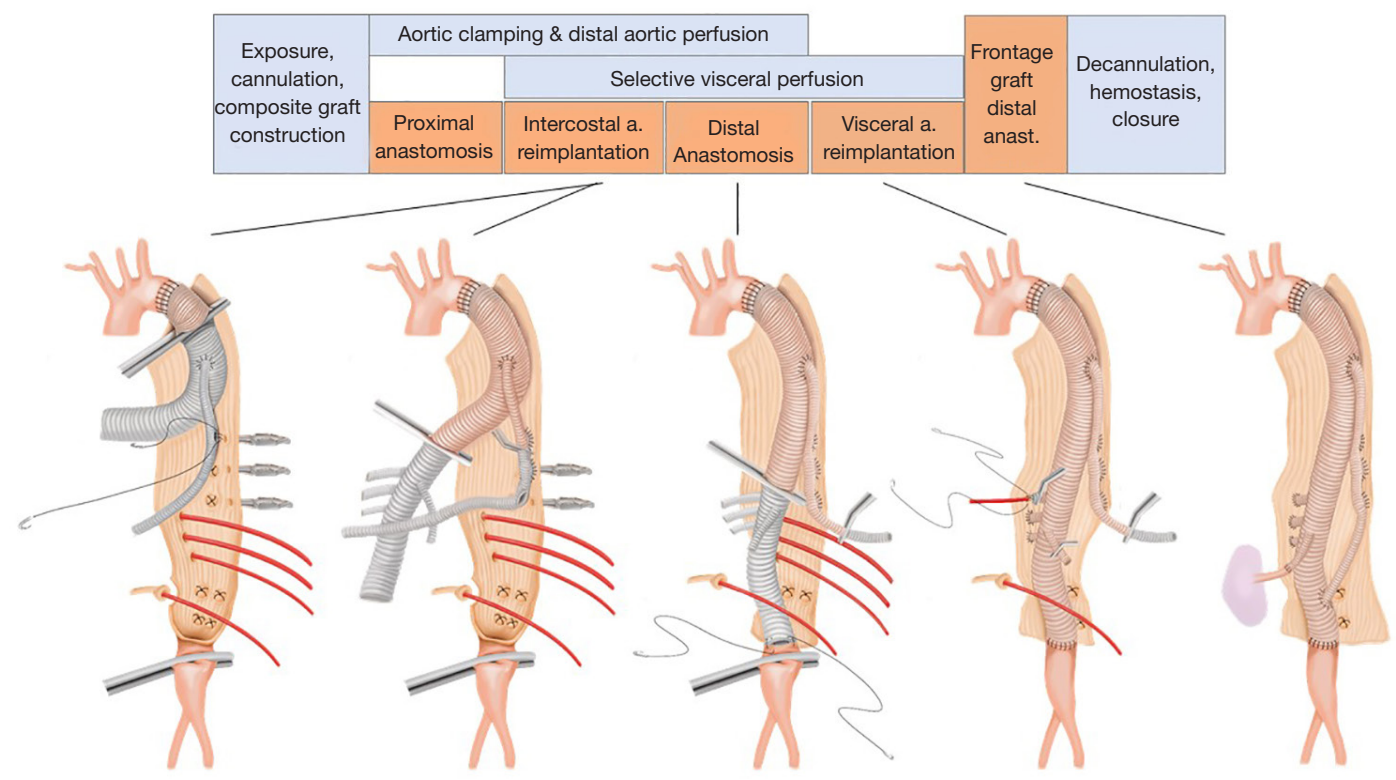

Figure 3 Timeline of the surgical procedure in extent II thoracoabdominal aortic aneurysm repair.

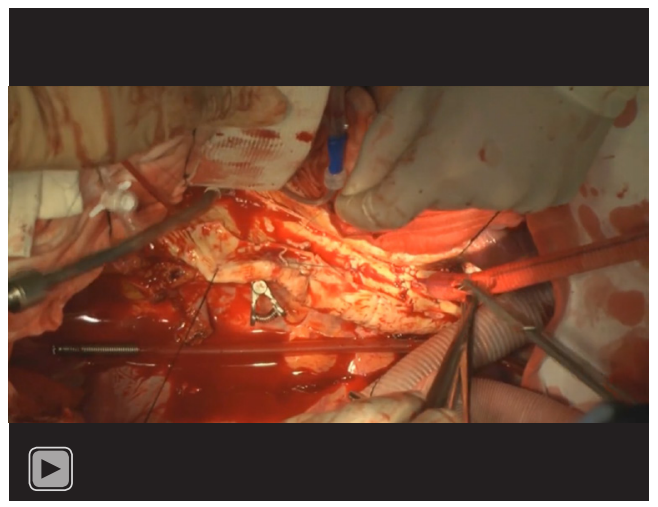

Video 1 Replacement of Crawford type II thoracoabdominal aortic aneurysm using a branched graft for reimplantation of the visceral and segmental arteries.

transesophageal echocardiographic probe, near-infrared spectroscopic cerebral oxygen monitor, nasopharyngeal and rectal temperature probes. In our practice, lumbar cerebrospinal spinal fluid (CSF) drainage catheter is inserted on the operation day just before positioning and draping the patient. The CSF catheter is opened to drain by gravity, while the hourly drainage amount is kept below $10 \mathrm{~mL}$. CSF pressure is not monitored.

The operation shown in Figure 3 and the attached video was proceeded as the following. The aorta was exposed via a curvilinear thoracoabdominal incision through the $6^{\text {th }}$ intercostal space. With the presence of the elephant trunk inserted during the previous surgery, proximal clamping was not a technical issue in this particular patient and did not require deliberate fracture of the $6^{\text {th }}$ rib which is frequently required in the other patients to gain better exposure of the proximal descending aorta near the arch. After transperitoneal exposure and medial rotation of the abdominal viscera followed by circumferential incision of the diaphragm (start of Video 1), exposure of the entire descending aorta was completed. We feel more comfortable with using what we call bar and wire technique instead of using self-retaining retractor blades.

Before clamping the aorta, we identified as many intercostal arteries as possible and all intercostal arteries above T7 level were closed with metal clips. At this stage, a 4-branch graft (Gelsoft ${ }^{\mathrm{TM}}$ Coselli, Terumo Aortic, Inchinnan, UK) was unpacked and tailored to the adequate length and a $10 \mathrm{~mm}$ knitted Dacron graft (Hemagard, Maquet GmbH \& Co., Rastatt, Germany) was attached to the proximal part of the aortic graft. After systemic heparinization, the left femoral artery and vein were cannulated for partial cardiopulmonary bypass, which has been our preferred method of distal aortic perfusion. The proximal anastomosis was performed while the proximal half of the descending thoracic aorta was isolated by segmental clamping and distal aortic perfusion was maintained by femorofemoral cardiopulmonary bypass. 

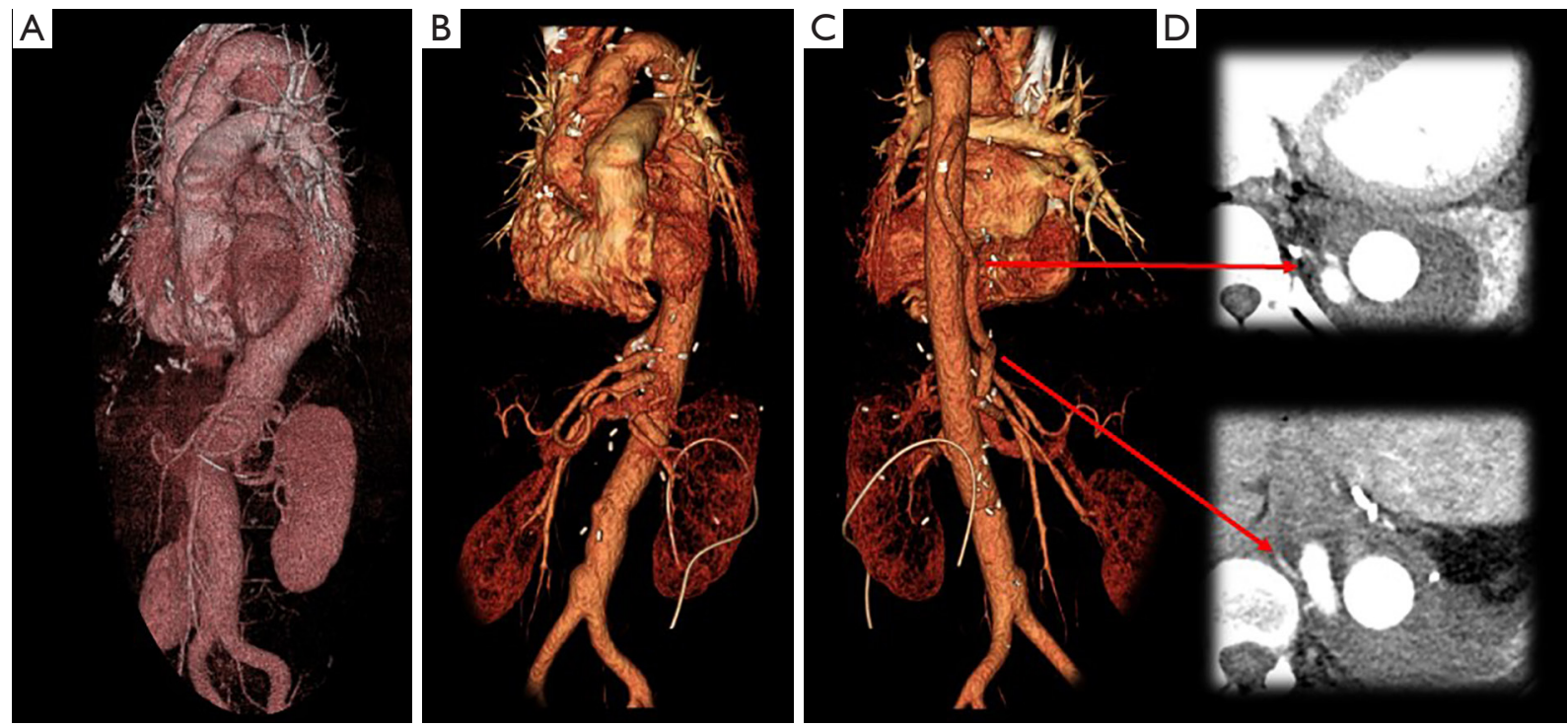

Figure 4 CT images of the case shown in the video; (A) preoperative, (B-D) postoperative images. The intercostal arteries reimplanted into the frontage graft at two levels were well visualized (arrows).

Then, the distal aortic clamp was moved to the infrarenal aorta and the remaining part of the TAA was longitudinally incised. The intercostal and lumbar arteries showing copious back-bleeding were rapidly obliterated with sutures, and the left sided intercostal arteries arising at 9 th and 12 th thoracic vertebra level were selected and temporarily occluded with bulldog clamps. Selective visceral perfusion using $9 \mathrm{Fr}$ and $12 \mathrm{Fr}$ balloon catheters $\left(\right.$ Pruitt $^{\circledR}$ catheter, LeMaitre Vascular, Burlington, USA) was started at this stage with the flow rate of $100 \mathrm{~mL} / \mathrm{min}$ per branch. And then, the intercostal arteries were sequentially anastomosed to the side of the parallel $10 \mathrm{~mm}$ graft. The size of the hole made in the graft was around $2 \mathrm{~cm}$ and 4-0 Prolene running suture was used. Reimplantation of one branch took 5 to 10 minutes.

As the next step, we performed the distal anastomosis of the main graft before reimplanting the visceral branches so that we could turn off the cardiopulmonary bypass at earlier stage. The visceral arteries were reimplanted in the sequence of right renal, superior mesenteric, celiac, and the left renal. Finally, the distal end of the parallel graft was anastomosed to the main graft under partial clamping (end of Video 1). The skin-to-skin total operation time was 299 minutes and the duration of femorofemoral bypass was 63 minutes.

The postoperative course was uneventful. The patient was extubated 3 hours after surgery and was moved out of the intensive care unit on the next day. The CSF drainage catheter was clamped at 24 hours after surgery and removed on the following day. She was discharged to home on the 11th day. In the CT scan taken before discharge, all visceral branches and both of the two reimplanted intercostal arteries were patent (Figure 4).

\section{Discussion}

\section{Advantage of branch graft technique}

Based on the huge experience of Crawford and his successors, i.e., Dr. Coselli and Dr. Safi, direct reimplantation of branch vessels as a large en bloc inclusion patch has been widely adopted as the standard technique of TAA replacement (1). Such technique may have some drawbacks as the following: (I) the suture line gets longer and requires more time for anastomosis when the reimplanted branches are widely apart as the result of severe dilatation of the corresponding aortic segment (2); (II) calcified plaques and muddy atheroma around the branches increase the difficulty of making secure and hemostatic anastomosis; (III) reperfusion of reimplanted intercostal arteries may be delayed in case the visceral reimplantation patch and low intercostal artery patch are close to each other making it difficult to clamp the graft between the two patches; (IV) reimplantation of branches arising from tortuous and angulated aorta as a large patch may cause angulation and torsion of the prosthetic graft; $(\mathrm{V})$ the large reimplantation patch may undergo late aneurysmal dilatation 
especially in patients with connective tissue disorder (3-5).

After advent of pre-sewn branched graft into the market, many surgeons adopted it in preference to the inclusion patch technique. Although there has been no study directly comparing the outcome of the two techniques, there seems to be no big difference in terms of the short-term outcome. The concern about the patency of branch grafts turned out to be irrelevant in case of visceral branch reimplantation because excellent patency rate was shown by a few studies (6-8).

\section{A parallel graft technique (frontage graft) for intercostal artery reimplantation}

In contrast to the visceral branch reimplantation, the patency rate of the interposition grafts reimplanting the intercostal arteries were shown to be suboptimal $(8,9)$. Such fact made us modify the reimplantation technique for intercostal arteries, in which the target branches were individually anastomosed in sequential manner to a parallel side graft attached to the main aortic graft at both ends. With this technique, the patency rate of reimplanted intercostal arteries significantly improved (Table 1), which seems to validate our speculation that the modified technique can have better patency by avoiding size mismatch between the interposition graft and the target arteries. In addition, we believe that our technique, named "frontage graft" after the service road running parallel to a highway, has advantages such as providing the versatility to deal with diverse anatomic situations, allowing a little faster reperfusion of the reimplanted intercostal arteries, and easier control of anastomotic bleeding, avoiding the risk of later patch aneurysm.

\section{Other tips and pitfalls}

(I) An important pitfall in using the Coselli graft is underestimating the marked distensibility of the graft thereby leaving excessive length between the proximal anastomosis and the origin of branch grafts. We decide where will be the proximal end of the graft after stretching it maximally while the origin of the first branch is kept at $5 \mathrm{~cm}$ above the origin of native celiac trunk. In our experience, 3 to $5 \mathrm{~cm}$ was adequate as the length of the branch grafts between their take-off and the anastomosis with the target visceral branches.

(II) It is also important to keep in mind that medial visceral rotation displaces the left kidney quite a lot from its original position and to make the left renal artery graft as short as possible in order to avoid redundancy. Overlooking such problem puts the graft at the risk of kinking (Figure 5) which may be a causative factor of the little higher occlusion rate of the left renal artery graft $(7,8)$.

(III) Anastomosis of the graft to branches having some amount of back-bleeding can be facilitated with good visibility by using a carbon dioxide blower which is commonly used for off-pump coronary artery bypass grafting.

(IV) The duration of extracorporeal circulation, whether it is left heart bypass or cardiopulmonary bypass, can be reduced by performing the distal aortic anastomosis before reimplanting the visceral branches while they are perfused selectively. In our experience, such distal-first sequence of anastomoses was easier to perform with branched grafts than with inclusion patch technique.

In conclusion, we believe that branch graft technique is more versatile and comfortable option for extensive TAA replacement. Our technique using a frontage graft for intercostal artery reimplantation is thought to have a few advantages with good patency rate of the target branches. 
Table 1 Operative data and outcome of thoracoabdominal aortic replacement with combined use of branched graft for visceral and frontage graft for intercostal artery reimplantation

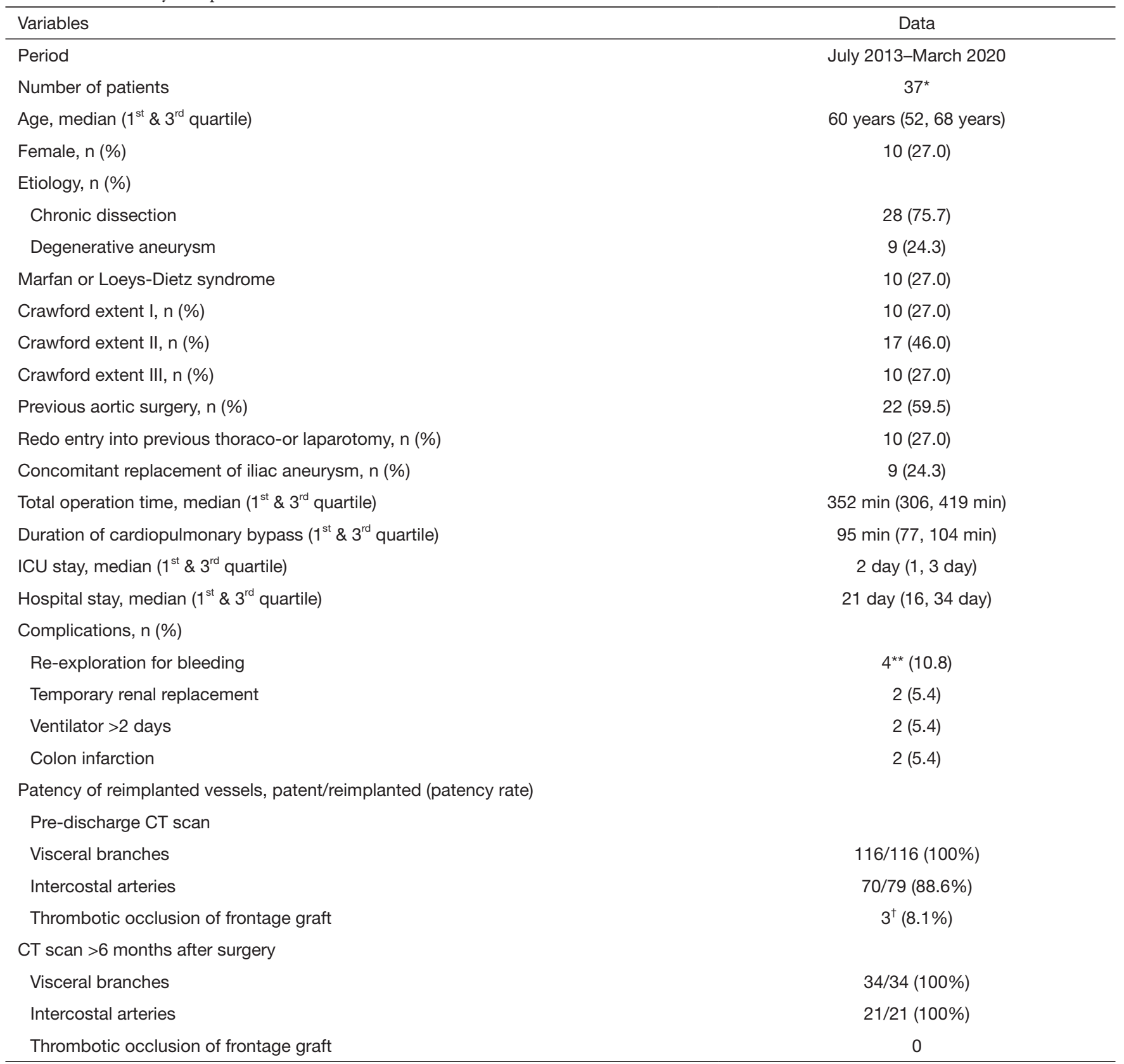

*, correspond to $30 \%$ of TAA replacement performed during the same period; ${ }^{*}$, only one of them was caused by anastomotic bleeding from the frontage graft; ${ }^{\dagger}$, total occlusion in one (the other two grafts were partially patent and supplied the reimplanted intercostal arteries via the non-occluded side). 


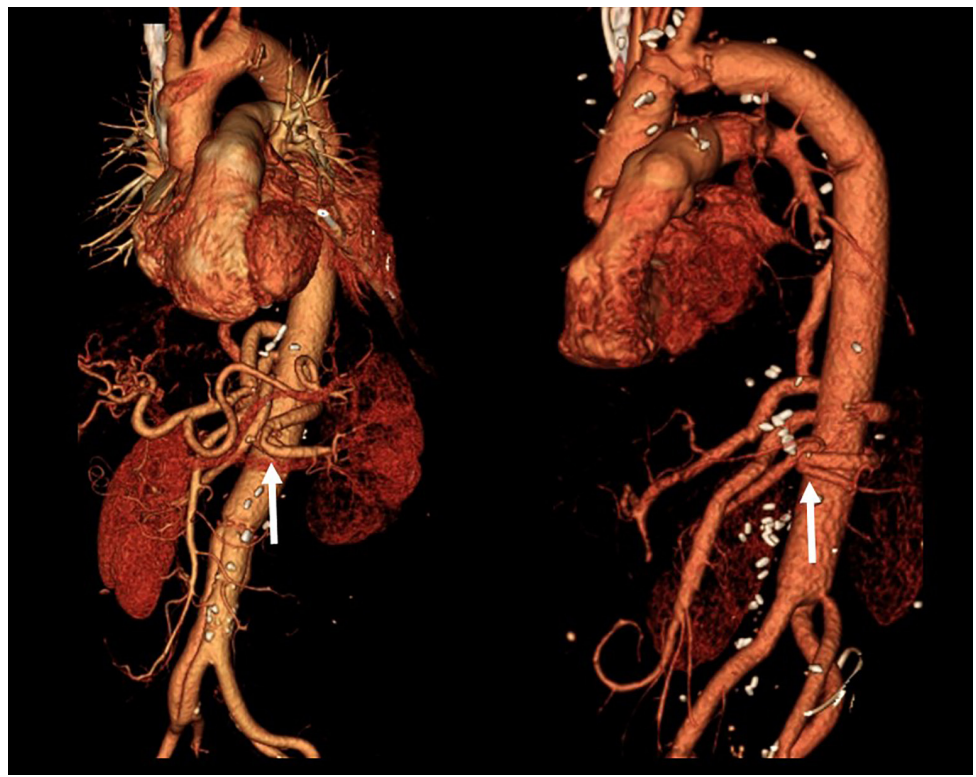

Figure 5 Angulation and kinking of the left renal artery caused by redundancy of the branch graft (arrows).

\section{Acknowledgments}

Funding: None.

\section{Footnote}

Provenance and Peer Review: This article was commissioned by the Guest Editors (Roberto Di Bartolomeo, Davide Pacini, Mohamad Bashir) for the series "Best Video Presentation Prize for the 10th Postgraduate Course on 'Surgery of the Thoracic Aorta' in Bologna" published in fournal of Visualized Surgery. The article has undergone external peer review.

Reporting Checklist: The authors have completed the CARE reporting checklist. Available at https://jovs.amegroups. com/article/view/10.21037/jovs-20-115/rc

Conflicts of Interest: Both authors have completed the ICMJE uniform disclosure form (available at https://jovs. amegroups.com/article/view/10.21037/jovs-20-115/coif). The series "Best Video Presentation Prize for the 10th Postgraduate Course on 'Surgery of the Thoracic Aorta' in Bologna" was commissioned by the editorial office without any funding or sponsorship. Both authors have no other conflicts of interest to declare.

Ethical Statement: The authors are accountable for all aspects of the work in ensuring that questions related to the accuracy or integrity of any part of the work are appropriately investigated and resolved. All procedures performed in this study were in accordance with the ethical standards of the institutional and/or national research committee(s) and with the Helsinki Declaration (as revised in 2013). Written informed consent was obtained from the patient for publication of this case report and accompanying images. A copy of the written consent is available for review by the editorial office of this journal.

Open Access Statement: This is an Open Access article distributed in accordance with the Creative Commons Attribution-NonCommercial-NoDerivs 4.0 International License (CC BY-NC-ND 4.0), which permits the noncommercial replication and distribution of the article with the strict proviso that no changes or edits are made and the original work is properly cited (including links to both the formal publication through the relevant DOI and the license). See: https://creativecommons.org/licenses/by-nc-nd/4.0/.

\section{References}

1. Coselli JS, de la Cruz KI, Preventza O, et al. Extent II thoracoabdominal aortic aneurysm repair: how I do it. Semin Thorac Cardiovasc Surg 2016;28:221-37.

2. de la Cruz KI, LeMaire SA, Weldon SA, et al. 
Thoracoabdominal aortic aneurysm repair with a branched graft. Ann Cardiothorac Surg 2012;1:381-93.

3. Dardik A, Perler BA, Roseborough GS, et al. Aneurysmal expansion of the visceral patch after thoracoabdominal aortic replacement: An argument for limiting patch size? J Vasc Surg 2001;34:405-9.

4. Tshomba Y, Melissano G, Civilini E, et al. Fate of the visceral aortic patch after thoracoabdominal aortic repair. Eur J Vasc Endovasc Surg 2005;29:383-9.

5. Kulik A, Allen BT, Kouchoukos NT. Incidence and management of intercostal patch aneurysms after repair of thoracoabdominal aortic aneurysms. J Thorac Cardiovasc Surg 2009;138:352-8.

6. Kouchoukos NT, Kulik A, Castner C. Branch graft patency after open repair of thoracoabdominal aortic aneurysms. J

doi: $10.21037 /$ jovs-20-115

Cite this article as: Park KH, Lee JH. Thoracoabdominal aorta replacement with branched graft for visceral and segmental artery reimplantation-case report. J Vis Surg 2022;8:27.
Thorac Cardiovasc Surg 2017;153:S14-9.

7. Hicks CW, Lue J, Glebova NO, et al. A 10-year institutional experience with open branched graft reconstruction of aortic aneurysms in connective tissue disorders versus degenerative disease. J Vasc Surg 2017;66:1406-16.

8. Kim SY, Chung S, Kim DJ, et al. Patency of branch vessels reimplanted during thoraco-abdominal aortic replacement: implications for the surgical technique. Eur J Cardiothorac Surg 2018;53:1027-33.

9. Henmi S, Ikeno Y, Yokawa K, et al. Comparison of early patency rate and long-term outcomes of various techniques for reconstruction of segmental arteries during thoracoabdominal aortic aneurysm repair. Eur J Cardiothorac Surg 2019;56:313-20. 